\title{
Unilateral neglect: the fate of the extinguished visual stimuli
}

\author{
P. D’Erme', I. Robertson², P. Bartolomeo ${ }^{1}$ and A. Daniele ${ }^{1}$ \\ 'Institute of Neurology, Neuropsychology Service, Catholic University, Rome, Italy, and \\ ${ }^{2}$ Medical Research Council, Applied Psychology Unit, Cambridge, UK
}

Correspondence to: P. D'Erme, Istituto di Neurologia, Università Cattolica del Sacro

Cuore, Largo A. Gemelli, 8, 00168 Rome, Italy

\begin{abstract}
Recent neuropsychological literature has provided evidence for the phenomenon of perception without awareness, also referred to as covert (or implicit) knowledge or tacit awareness. Yet little is known to date about the fate of extinguished stimuli in patients with unilateral spatial neglect. Six right brain-damaged patients with USN and one control subject were presented with single lateralized visual stimuli and with pairs of same or different visual stimuli (one right, one left). A same/different judgement and a multiple choice recognition task were performed on overtly unidentified left-sided stimuli, to unveil possible phenomena of covert knowledge. Some evidence of covert knowledge was observed, and its relation to stimulus characteristics and task demands is discussed.
\end{abstract}

Keywords: Covert knowledge - Extinguished stimuli - Neglect

\section{INTRODUCTION}

In various neurological and neuropsychological syndromes patients may lack awareness of some information that still undergoes a certain degree of processing. This phenomenon of covert knowledge can be detected under appropriate experimental conditions, which enable the patients to give accurate responses or make judgements about the overtly missed piece of information.

Examples of "knowledge without awareness" were first observed in patients with visual field defect, who showed evidence of "blind sight" (Poeppel et al., 1973; Weiskrantz et al., 1974; Blythe et al., 1987; Weiskrantz, 1987). Paillard et al. (1983) described a patient with a severe hemianaesthesia, showing an analogue of blind sight in the tactile modality. Moreover, some patients with prosopoagnosia may show a considerable degree of recognition of familiar faces if tested on tasks that do not demand explicit identification: such patients are unaware that recognition has been achieved (Bruyer et al., 1983; Bauer, 1984; Tranel and Damasio, 1985; De Haan et al., 1987a, 1987b, 1992; Bruyer, 1991). Likewise, Graf and Schacter (1985) put forward the distinction between explicit and implicit memory, the latter being an unconscious recollection of information. Hartmann et al. (1991) observed a patient showing a "denial of visual perception" (also described by the authors as an "inverse Anton's syndrome"), who was able to access and utilize visual infor-

(C) 1993 Rapid Communications of Oxford Ltd mation, without being aware that the input modality was visual.

So far, few studies have taken into account the possible occurrence of phenomena of covert knowledge in patients with visual extinction and unilateral neglect.

Volpe et al. (1979) examined four right brain-damaged patients with full visual field and left-sided visual and tactile extinction; these patients were not explicitly reported to present with neglect. In the crucial experiment, lateralized visual stimuli (words or pictures) were simultaneously presented in both visual fields. The authors reported in all patients a high accuracy of same/different judgements between right- and left-sided visual stimuli in trials in which the patients could not afterwards name, and sometimes even denied the presence of, the left field stimulus. Thus, on the critical "different" trials, two patients were able to name only a small number of left stimuli, whereas the other two patients could not name any stimulus but showed none the less some degree of processing of the extinguished stimuli, as suggested by the accuracy of the same/different judgements.

Volpe et al. (1979) argued that a breakdown in the flow of information between conscious and non-conscious mental systems accounts for the phenomena of covert knowledge of extinguished stimuli.

Similar findings were obtained by Karnath and Hartje 
(1987) from a patient with left-sided neglect, who was able to correctly perform the same/different judgements and to name about $50 \%$ of the left-sided visual stimuli on the "different" trials. An automatic processing on a preattentional level was hypothesized by the authors to account for these data. Both studies used brief exposure times and a central fixation of gaze was required.

Marshall and Halligan (1988) described a right braindamaged patient with left hemianopia and severe leftsided neglect. This patient was shown, with unlimited viewing time and free vision, two line drawings of a house, in one of which red flames were emerging from the left side of the house. In being asked to judge whether the two houses were the same or different, the patient failed to overtly notice any difference between the two pictures, but consistently selected the non-burning house when forced to say in which one she would prefer to live. Thus, a tacit awareness of a critical left-sided feature was uncovered. Bisiach and Rusconi (1990) recently pointed out that they were not able to unambiguously replicate Marshall and Halligan's findings in a small group of neglect patients.

The phenomenon of covert knowledge was recently investigated in one right brain-injured patient by Berti $e t$ al. (1992); they speculated that correct same/different judgements on pairs of objects (simultaneously presented in both visual hemifields) were based in their patient on categorical information rather than on low level visual features or on information about the object identity.

In this study we tried to clarify whether and to what extent information about the left hemispace may be "preconsciously" processed in neglect patients and whether different aspects of the phenomenon might be observed among patients as related to performances in different tasks. If neglected stimuli are still somehow processed, we should expect that under varying experimental conditions different levels (or kinds) of covert stimulus processing might be revealed in each patient. According to Volpe et al. (1979) the same/different judgement is carried out at a postperceptual, preverbal level. We assumed that a multiple choice recognition task would explore a different level of processing (or, alternatively, a different kind of processing) compared with the same/different judgement. A forced choice task requires in fact the access to a greater amount of information compared with the same/different judgement and, on the other hand, it does not necessarily imply a full conscious identification of the stimulus, compared with the recall task. If this were the case, greater evidence of implicit knowledge of the omitted stimuli should be found in the same/different judgement condition compared with the multiple choice recognition task, either within or across patients. Alternatively, if the two tasks explore different kinds or routes of processing, we might find evidence of covert knowledge of the extinguished stimuli in one task independently of the other within a single subject's performance.

The possible influence of the stimulus characteristics (i.e. verbal vs non-verbal stimuli) on the rate of extinction and on the possible phenomena of covert knowledge was also taken into account.

\section{METHODS}

\section{Subjects}

Six right brain-damaged patients entered this study. They underwent careful clinical examination and laboratory assessment (including CT scan); their main demographic and clinical characteristics are reported in Table I. A 52year-old healthy control subject was also examined.

All patients had full visual field capacity as tested by a standard perimeter. Patients were preliminarily given a test battery for assessment of hemi-neglect including tasks of letter cancellation, line bisection (D'Erme et al., 1987), Albert's line cancellation test (Albert, 1973), copy of horizontally arrayed line drawings (Gainotti et al., 1986), identification of overlapping figures (Gainotti et al., 1986) and the "Searching for Animals" test (Gainotti et al., 1986). A frequency of left-sided omissions of $20 \%$ of the overall items of each test was adopted as cut-off score to distinguish between mild and moderate-severe neglect; in the line bisection tasks the cut-off was represented by a

TABLE I. Main demographic and clinical characteristics of the subjects

\begin{tabular}{|c|c|c|c|c|c|c|c|c|}
\hline Subject & Age & $\begin{array}{l}\text { Years of } \\
\text { schooling }\end{array}$ & $\begin{array}{c}\text { Right } \\
\text { hemispheric } \\
\text { lesion site }\end{array}$ & Aetiology & $\begin{array}{c}\text { Time since } \\
\text { onset of } \\
\text { symptoms }\end{array}$ & $\begin{array}{l}\text { Visual } \\
\text { field } \\
\text { defect }\end{array}$ & $\begin{array}{c}\text { Visual } \\
\text { extinction }\end{array}$ & Neglect \\
\hline 1 & 55 & 5 & Temporal & Neoplastic & 1 week & No & Systematic & Moderate-severe \\
\hline 2 & 74 & 12 & Frontal-parietal & Ischaemic & 1 year & No & Systematic & Moderate-severe \\
\hline 3 & 68 & 9 & Parietal-occipital & Ischaemic & 1 month & No & Systematic & Moderate-severe \\
\hline 4 & 56 & 8 & Temporal & Ischaemic & 3 months & No & Systematic & Mild \\
\hline 5 & 54 & 6 & Frontal-parietal & Ischaemic & 2 years & No & Systematic & Mild \\
\hline 6 & 49 & 8 & Parietal-occipital & Ischaemic & 1 week & No & None & Minimal findings \\
\hline $\begin{array}{l}\text { Control } \\
\text { subject }\end{array}$ & 52 & 13 & - & - & - & - & - & - \\
\hline
\end{tabular}

144 Behavioural Neurology . Vol 6. 1993 


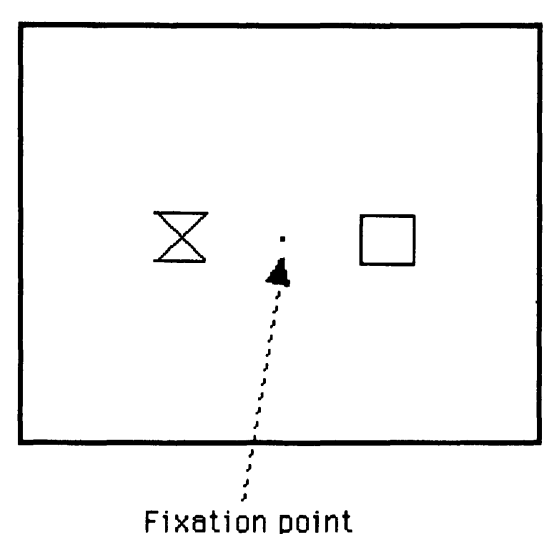

Fixation point

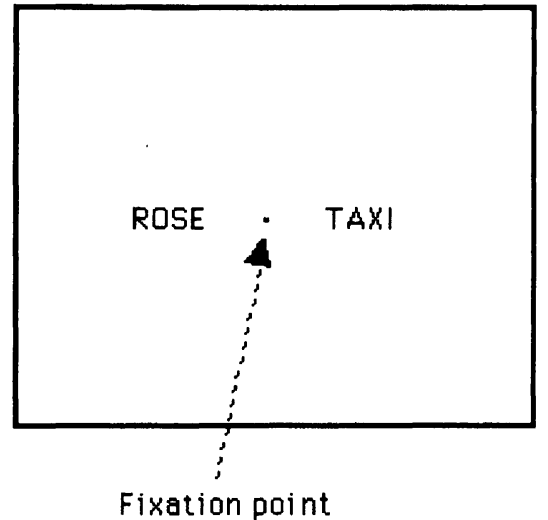

Fixation point

FIG. 1. Two examples of double presentation of shapes and words.

$10 \%$ mean displacement towards the right side of the subjective centre. Patients were respectively classified as showing mild neglect or moderate-severe neglect when remaining below or exceeding the cut-off score in the majority of tasks. Further, the occurrence of visual extinction on bilateral simultaneous stimulation was clinically tested using the confrontation technique.

\section{Procedures}

The experiment was carried out on a computer with a 17.5 by $13.5 \mathrm{~cm}$ screen. The subject sat in a dimly illuminated room, facing the computer screen at a distance of $30 \mathrm{~cm}$, with the centre of the screen at eye level. The head was supported by a chin and forehead rest apparatus. Eye fixation on a dot located on the centre of the screen was visually monitored by an experimenter standing behind the computer. We presented non-verbal and verbal lateralized stimuli (Fig. 1), singly or doubly (one left, one right); the stimuli appeared at a distance of about $2.4 \mathrm{~cm}$ to the left or right of the fixation point.

Non-verbal stimuli consisted of five simple shapes: circle, cross, diamond, hollow square, black square. The shapes subtended visual angles of about $1^{\circ} 22^{\prime}$ by $1^{\circ} 22^{\prime}$. Verbal stimuli consisted of four-letter Italian nouns, matched for both frequency and imageability. The words subtended visual angles of about $1^{\circ} 43^{\prime}$ by $34^{\prime}$. In both the shapes and the words sessions the standard exposure time (ET) was $183 \mathrm{~ms}$, that is below eye saccade latency.

Patient 3 was not submitted to the words session due to technical problems and Patient 4 was discharged from the hospital prior to the administration of the shapes session.

In the session with single lateralized stimuli (see Table II) we determined whether each patient was able to perform the task at the established ET of $183 \mathrm{~ms}$. This ET was sufficient to allow accurate identification of all right-sided stimuli (shapes and words) in most patients. However for Patients 1 and 2, who showed a moderate-severe neglect, this ET was too brief to allow accurate identification of
TABLE II. Results obtained by six right brain-damaged patients and one control subject on unilateral presentation of shapes and words

\begin{tabular}{|c|c|c|c|c|}
\hline \multirow[t]{2}{*}{ Subjects } & \multicolumn{2}{|c|}{$\begin{array}{l}\text { Right-sided stimuli: } \\
\text { omissions }\end{array}$} & \multicolumn{2}{|c|}{$\begin{array}{l}\text { Left-sided stimuli: } \\
\text { omissions (+ errors) }\end{array}$} \\
\hline & $\begin{array}{l}\text { Shapes } \\
(n=5)\end{array}$ & $\begin{array}{l}\text { Words } \\
(n=5)\end{array}$ & $\begin{array}{l}\text { Shapes } \\
(n=10)\end{array}$ & $\begin{array}{l}\text { Words } \\
(n=10)\end{array}$ \\
\hline 1 & 0 & $0^{*}$ & 3 & $7^{\star}$ \\
\hline 2 & $0^{\star \star}$ & $0^{\star \star \star}$ & $0^{\star \star}$ & $6^{\star \star}$ \\
\hline 3 & 0 & - & 0 & - \\
\hline 4 & - & 0 & - & $0(+4)$ \\
\hline 5 & 0 & 0 & 1 & 1 \\
\hline 6 & 0 & 0 & 0 & 0 \\
\hline Control subject & 0 & 0 & 0 & 0 \\
\hline
\end{tabular}

even single right-sided stimuli. Thus, for Patient 1 in the words session the ET was lengthened to $300 \mathrm{~ms}$; for Patient 2 it was lengthened to $700 \mathrm{~ms}$ for the shapes and $1000 \mathrm{~m}$ for the words.

In both the shapes and the words sessions, subjects were at first given single stimuli, namely five right and 10 left stimuli in a randomized order, and asked to report what they had seen. Afterwards, subjects were told that two stimuli would appear on the screen, one on each side of fixation. Twenty pairs of different stimuli were presented in both sessions, while five pairs of identical shapes and 10 pairs of identical words were presented in the respective sessions. In both sessions the "same" and "different" trials were presented in a previously randomized order.

The responses associated with eye movements were not considered, and this accounts for the unequal number of responses obtained from Patients 2 and 5 in the words session.

On the bilateral presentation, subjects were at first asked to report what they had seen (recall task). By the term "omission" we shall refer to lack of recall of the 
stimulus, independently of the patient's feeling that "something" appeared, as in Volpe et al.'s (1979) paper. On this task both omissions and errors were taken into account as incorrect responses.

In all instances of bilateral presentation on which no recollection of the left-sided stimulus occurred (i.e. on omitted left-sided stimuli), subjects were first asked to guess whether a hypothetical stimulus on the left was the same or different to that on the right (same/different judgement task, SDJ). Then, only when a correct SDJ was made on a "different" trial, subjects were given a five item vertical list of stimuli (Fig. 2), one of which was the omitted left-sided stimulus, and were asked to guess which one had appeared on the left (multiple choice recognition task,
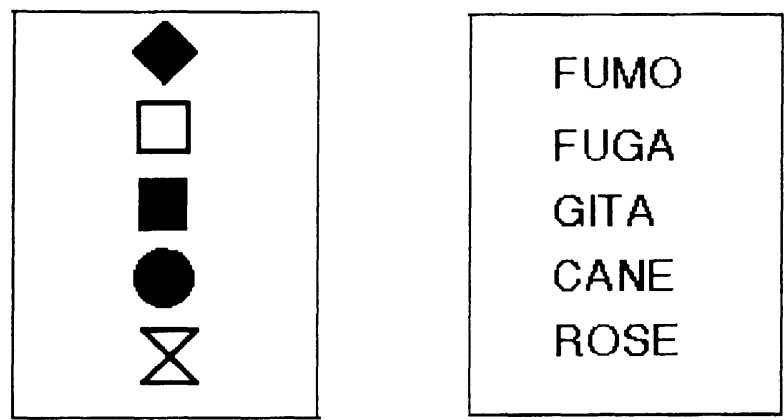

FIG. 2. Items from the multiple choice lists for the shapes session (left) and for the words session (right).
MCRT). In our paradigm, the "different" trials were considered to be critical since, as also stressed by Volpe et al. (1979), the name of the left stimulus could not be deduced from the right one. A proportion of $50 \%$ correct responses on the SDJ and $20 \%$ on the MCRT corresponds to "chance level", thus indicating a random performance. Both the shapes and the words sessions were preceded by practice trials.

\section{RESULTS}

Results of double simultaneous presentation are reported in Tables III and IV. The control subject showed no omission of stimuli both in the shapes and in words sessions. His overall performance was considerably accurate; however, in the words session he made some errors (namely single-letter substitutions).

In the neglect group, the performance of Patients 2 and 5 shows up in the SDJ and MCR tasks for possible evidence of covert knowledge. Patient 2 omitted nine left-sided stimuli (two same, seven different) in the shapes session; on the SDJ she answered "different" on all omitted stimuli. The accuracy of the MCRT performed on the same stimuli was not above the chance level (about $14 \%$ of correct responses). In the words session she was not able to recall the left stimulus on 14 trials (two out of three "same" trials and 12 out of 20 "different" trials). On 11 trials she said that "something" had appeared on the left, whereas in three trials she did not notice any left-sided stimulus. On the

TABLE III. Results obtained by five right brain-damaged patients and one control subject on presentation of pairs of shapes

\begin{tabular}{|c|c|c|c|c|c|}
\hline \multirow[t]{2}{*}{ Subject } & \multicolumn{2}{|c|}{$\begin{array}{c}\text { Recall, } \\
\text { omissions (+ errors) }\end{array}$} & \multicolumn{2}{|c|}{$\begin{array}{l}\text { Same/different judgement, } \\
\text { correct responses/left } \\
\text { omissions }\end{array}$} & \multirow[t]{2}{*}{$\begin{array}{l}\text { Multiple choice task, correct } \\
\text { recognitions/correctly } \\
\text { judged different stimuli }\end{array}$} \\
\hline & $\begin{array}{l}\text { Same pairs } \\
\quad(n=5)\end{array}$ & $\begin{array}{l}\text { Different pairs } \\
\quad(n=20)\end{array}$ & Same pairs & Different pairs & \\
\hline \multicolumn{6}{|l|}{1} \\
\hline $\mathrm{R}$ & 0 & $0(+5)$ & & & \\
\hline L & $2(+1)$ & $14(+3)$ & $1 / 2$ & $8 / 14$ & $1 / 8$ \\
\hline \multicolumn{6}{|l|}{$2^{\star}$} \\
\hline $\mathrm{R}$ & 0 & 0 & & & \\
\hline L & 2 & 7 & $0 / 2$ & $7 / 7$ & $1 / 7$ \\
\hline \multicolumn{6}{|l|}{3} \\
\hline $\mathrm{R}$ & 0 & 0 & & & \\
\hline L & 5 & 20 & $0 / 5$ & $18 / 20$ & $2 / 18$ \\
\hline \multicolumn{6}{|l|}{5} \\
\hline R & 0 & $0(+1)$ & & & \\
\hline L & $1(+1)$ & $2(+2)$ & $1 / 1$ & $2 / 2$ & $2 / 2$ \\
\hline \multicolumn{6}{|l|}{6} \\
\hline $\mathrm{R}$ & 0 & 0 & & & \\
\hline L & 0 & 0 & - & - & - \\
\hline \multicolumn{6}{|c|}{ Control subject } \\
\hline $\mathbf{R}$ & 0 & 0 & & & \\
\hline $\mathrm{L}$ & 0 & 0 & - & - & - \\
\hline
\end{tabular}

Exposure time $(E T)=183 \mathrm{~ms}\left({ }^{*} E T=700 \mathrm{~ms}\right), \mathrm{R}=$ right; $\mathrm{L}=$ left. 
TABLE IV. Results obtained by five right brain-damaged patients and one control subject on presentation of pairs of words

\begin{tabular}{|c|c|c|c|c|c|}
\hline \multirow[t]{2}{*}{ Subject } & \multicolumn{2}{|c|}{$\begin{array}{c}\text { Recall, } \\
\text { omissions (+ errors) }\end{array}$} & \multicolumn{2}{|c|}{$\begin{array}{l}\text { Same/different judgement, } \\
\text { correct responses/left } \\
\text { omissions }\end{array}$} & \multirow[t]{2}{*}{$\begin{array}{l}\text { Multiple choice task, correct } \\
\text { recognitions/correctly } \\
\text { judged different stimuli }\end{array}$} \\
\hline & $\begin{array}{l}\text { Same pairs } \\
\quad(n=5)\end{array}$ & $\begin{array}{l}\text { Different pairs } \\
\quad(n=20)\end{array}$ & Same pairs & Different pairs & \\
\hline \multicolumn{6}{|l|}{$1^{\star}$} \\
\hline $\mathrm{R}$ & $0(+3)$ & $0(+5)$ & & & \\
\hline L & 10 & 19 & $1 / 10$ & $18 / 19$ & $3 / 18$ \\
\hline \multicolumn{6}{|l|}{$2^{\star \star *}$} \\
\hline $\mathrm{R}$ & $0(n=3)$ & 0 & & & \\
\hline$L$ & $2(n=3)$ & 12 & $1 / 2$ & $\begin{array}{c}6 / 6 \\
(+6 \text { refusals) }\end{array}$ & $6 / 12$ \\
\hline \multicolumn{6}{|l|}{4} \\
\hline $\mathrm{R}$ & $2(+3)$ & $5(+7)$ & & & \\
\hline L & 3 & 6 & $0 / 3$ & $6 / 6$ & $1 / 6$ \\
\hline \multicolumn{6}{|l|}{5} \\
\hline $\mathrm{R}$ & $0(n=8)$ & $0(+2)$ & & & \\
\hline L & $2(n=8)$ & $5(+3)$ & $0 / 2$ & $5 / 5$ & $1 / 5$ \\
\hline \multicolumn{6}{|l|}{6} \\
\hline $\mathrm{R}$ & 1 & $1(+4)$ & & & \\
\hline L & 1 & $1(+11)$ & $0 / 1$ & $1 / 1$ & $1 / 1$ \\
\hline \multicolumn{6}{|c|}{ Control subject } \\
\hline $\mathrm{R}$ & 0 & $0(+1)$ & & & \\
\hline L & 0 & $0(+4)$ & - & - & - \\
\hline
\end{tabular}

Exposure time $(E T)=183 \mathrm{~ms}\left({ }^{\star} E T=300 \mathrm{~ms} ;{ }^{* *} E T=1000 \mathrm{~ms}\right), R=$ right; $L=$ left.

SDJ she was correct in one out of two "same" trials (on that trial on which she had noticed "something" on the left) and in six out of 12 "different" trials (on all these six trials she had noticed "something" on the left); in the remaining six "different" trials she refused to perform the SDJ, stating that "it was a silly task" since she had no notion whatsoever about the stimulus. Thus, the accuracy of her SDJ on words was at chance level. None the less, on all of the 12 "different" trials she agreed to subsequently perform the MCRT, and was able to correctly recognize six out of 12 "not recalled" left stimuli. Interestingly, four out of the six correct responses on the MCRT were given on trials on which she had resolutely refused to perform the SDJ, while the other two correct responses were on trials on which she had correctly performed the SDJ. The accuracy of performance was above chance level in the MCRT, the overall proportion of correct responses being 50\%, compared with a chance level of $20 \%$. The raw data relative to this performance were subjected to a Fisher's exact probability test that showed a trend toward statistical significance (one-tailed probability $=0.078$ ).

Patient 5 in the shapes session omitted three left-sided stimuli; on all the omitted stimuli she performed accurate SDJ (100\% correct responses) and on the two "different" trials she was able to correctly perform the MCRT (100\% of correct responses). In the words session she made seven left-sided omissions; when asked to perform the SDJ she always answered "different" and on the five "different" trials she gave only one correct response on the MCRT (chance level).

Patient 1 showed in both the shapes and the words sessions a large number of left-sided omissions and on the corresponding "different" trials he was not able to perform the MCRT at above chance level. The correct responses in the SDJ of the shapes session were one out of two "same" trials and eight out of 14 "different" trials (accuracy level $=56 \%$ ); in the words session he answered "different" on nine out of the 10 "same" trials and on 18 out of the 19 "different" trials.

Patient 3 showed an accurate detection of single stimuli as opposed to systematic omission of all left-sided stimuli on double presentation. On the SDJ he answered "different" on all the five "same" trials and on 18 out of the 20 "different" trials. He was not able to perform the MCRT at above chance level.

Patient 4, although presenting a clear-cut left-sided neglect on standard neuropsychological examination, somewhat surprisingly showed a large number of omissions and errors in the right hemifield; particularly, in three instances of "same" trials the patient accurately read the word, placing it in the left hemifield, at the same time misreading the (identical) stimulus which he perceived on the right side. Patient 4 , as is uncommonly seen, was highly concerned about his neglect and this could suggest that he spontaneously adopted some kind of compensatory strategies at the expense of an accurate scanning of the 
right hemifield. As regards the left hemispace, Patient 4 omitted nine words, all of which were judged as "different" on the SDJ task; he was not able to perform the MCRT at above chance level.

Patient 6 made neither errors nor omissions in the shapes session. In the words session, however, she made 11 left-sided errors (mostly single letter substitutions) and four right-sided errors on "different" trials; moreover, she omitted two right-sided words and two left-sided words. On the "same" word trial she failed to correctly perform the SDJ, whereas on the "different" trial she was able to accurately perform both the SDJ and the MCRT.

Taking into account the performance of the group of neglect patients, a similar incidence of left-sided extinctions on the "same" pairs compared with the "different" pairs of stimuli was found either in the shapes or in the words session. A chi-squared analysis comparing the number of correct and omitted stimuli from the "same" and from the "different" pairs yielded a non-significant result for the shapes session $\left(\chi^{2}=0.065 ; p=0.68\right)$ and for the words session $\left(\chi^{2}=0.607 ; p=0.44\right)$.

In the SDJ task most patients show a clear trend to report that the "extinguished" left-sided stimulus was "different" from the right-sided one (also in the "same" trials). Thus, in this context, an accurate response should entail correct "same" judgements on all "same" trials; this, however, was observed only in Patient 5 on the shapes session.

The accuracy of responses on the MCRT was above chance level in Patients 2 and 6 (words session) and in Patient 5 (shapes session).

We shall now briefly consider the influence of the characteristics of the stimulus on the patients' performance. Patients 3 and 4 are excluded from this analysis, as they did not carry out both the shapes and the words sessions. Noticeably, Patients 1 and 2 needed longer ETs for the recognition of words than of shapes.

Summing up, left-sided omissions and errors of braindamaged patients in the words session compared with the shapes session, a proportion of 35 errors out of 100 shapes, and 66 errors out of 111 was obtained, with a $\chi^{2}$ of 12.61 and $p<0.0004$. A marked prevalence of left-sided errors and omissions is thus observed in the naming of words compared with shapes.

\section{DISCUSSION}

Some evidence of covert knowledge of extinguished leftsided visual stimuli was observed in our series in two patients out of six. Patient 2 performed in the MCRT of the words session with an above chance level of accuracy, and Patient 6 correctly performed both the SDJ and the MCRT on the shapes she had omitted on the left side. On the other hand, there was no reliable evidence of covert knowledge in Patients 1, 3 and 4. In the case of Patient 6 neglect was very mild and, though she made many errors in the recall of left-sided words, the extinction rate was too low for the purposes of covert recognition detection.

An influence of the stimulus characteristics on the outcome of visual processing in neglect patients might account for the dissociation between performances in the words and shapes session. In fact, whereas Patient 2 showed signs of covert recognition of omitted words but not of shapes, the opposite pattern was found in Patient 5, who achieved correct SDJ and MCRT of omitted shapes but not of omitted words. This dissociation appears more striking if we consider that shapes' recognition was easier than words' recognition by the group of neglect patients, as shown by the finding that the percentage of extinctions in the shapes session is significantly lower than that in the words session. We might thus have expected to find more clear signs of covert knowledge in the condition in which processing was mainly based on low level visual features (i.e. shapes), than in the words condition, but this was not the case. A tentative interpretation of this finding is that in our patients the complexity of the stimulus influences the outcome of visual processing only at a perceptual level, so that the access to a postperceptual level is far less probable for the words than for the shapes; once a stimulus has none the less achieved a postperceptual level, its preconscious processing might follow different routes, which can be separately damaged, giving rise to evidence of covert knowledge independently for one or the other type of stimulus. In fact, an alternative explanation should acknowledge that a greater obstacle is encountered by words than by shapes in flowing from a preconscious towards a conscious level of processing: if this were the case, then a postperceptual level should have been equally achieved by both types of stimuli, and the fate of the greater number of extinguished words should be traced by tasks of covert recognition more frequently than that of shapes, which was not found.

Volpe et al. (1979), who also utilized both words and pictures, did not give separate data for these different classes of stimuli. Farah et al. (1991) challenged Volpe's hypothesis of an impaired access of extinguished stimuli to conscious awareness, raising the possibility that poor perception of stimuli might account for dissociations in performance between same/different matching tasks and identification tasks. According to Farah et al. (1991), the same/different matching might be easier to perform than the identification tasks, requiring a smaller amount of information about the stimulus. However, Farah and coworkers' hypothesis does not fully account for the fact that some patients strongly deny the very existence of any left-sided stimulus, rather than reporting that "something" was presented.

In fact, as seems to be the case for Patients 1 and 2 in Volpe et al.'s series (1979), no information at all about the 
extinguished stimulus does apparently enter consciousness. However, in other instances, some pieces of information about the extinguished stimulus do spontaneously enter consciousness. This applies to our Patients 2 and 5 and to Patients 3 and 4 in the series by Volpe et al. (1979), who were often aware of the presence of the stimulus. Yet the latter behaviour is often found associated with the former within the same session in Volpe et al.'s patients and in our Patient 2. Interestingly, an analogous heterogeneity has been observed also in patients with different phenomena of "covert knowledge". As suggested by Blythe et al. (1987) for patients with visual field defects, the term "blind sight" should refer to those phenomena occurring without the subject being aware of them, whereas in patients with so-called "residual vision" some conscious (although not complete) visual percept is registered. Thus it would be advisable that in studies of covert knowledge the subjects' judgement about the presence or absence of the extinguished stimuli be always specified, to better assess in which instances covert knowledge occurs or is more frequent.

Although no significant difference was found between the rate of extinction of left-sided stimuli in the "same" pairs compared with the "different" pairs, most patients showed a trend in always giving. "different" responses both on the "same" and the "different" pairs in either the shapes or the words session of the SDJ task. Different reasons might account for this trend: firstly, a stimulus that has not been reported or fully recognized on the left side might actually be experienced by the patient as something different from whatever had clearly appeared on the righthand side. It should also be pointed out that the order of presentation of the recall task and of the SDJ is reversed in our study compared with Volpe et al.'s study (1979): patients were here requested to make a same/different judgement on a pair of stimuli only after having failed to name the left-sided one, whereas in Volpe's study the SDJ preceded the naming task. Secondly, a strategical bias might result from the number of "different" pairs of stimuli exceeding that of the "same" pairs in our study.

The MCRT was the last task performed by the patients in each session; as pointed out by Karnath (1988) in a different context, the accuracy of performance in this task might have been unfavourably influenced by this order of presentation. However, the fairly accurate performance obtained by Patient 2 on the words session of this task, as opposed to a random performance (if refusals are taken into account) in the SDJ, might be tentatively interpreted by assuming that the two tasks rely on different kinds of processing which might be separately affected in neglect patients. This finding can be reconciled with the alternative prediction outlined in the Introduction.

Thus, distinct and independent evidence of covert knowledge might be uncovered in some neglect patients under different experimental conditions. This suggestion, being based on preliminary data, needs be confirmed by further study; however, it can be reconciled with Bruyer's (1991) findings of inconsistent evidence of covert face recognition across different tasks in the same patient.

On the other hand, complete oblivion appears to be the fate of the extinguished visual stimuli in a good number of the neglect patients of our series, in which no access whatsoever to a preconscious level of visual processing is achieved.

Although claiming that no current evidence is available for unconscious perception in extinction, Farah et al. (1991) also admitted that "it is possible that some patients with extinction do show unconscious perception of extinguished stimuli, while others do not" (p. 956). Observed from the latter viewpoint, the results of our study confirm that a covert knowledge of extinguished stimuli does represent an uncommon event among patients with left-sided extinction or neglect.

\section{REFERENCES}

Albert ML (1973) A simple test of visual neglect. Neurology, 23, 658-664.

Bauer RM (1984) Autonomic recognition of names and faces in prosopoagnosia: a neuropsychological application of the guilty knowledge test. Neuropsychologia, 22, 457-469.

Berti A, Allport A, Driver J, Dienes Z, Oxbury J and Oxbury S (1992) Levels of processing of visual stimuli in an "extinguished" field. Neuropsychologia, 30, 403-415.

Bisiach E and Rusconi ML (1990) Break-down of perceptual awareness in unilateral neglect. Cortex, 26, 643-649.

Blythe IM, Kennard C and Ruddock KH (1987) Residual vision in patients with retrogeniculate lesions of the visual pathways. Brain, 110, 887-905.

Bruyer R (1991) Covert face recognition in prosopoagnosia: a review. Brain and Cognition, 15, 223-235.

Bruyer R, Laterre C, Seron X, Feyereisen P, Strypstein E, Pierrard E and Rectem D (1983) A case of prosopoagnosia with some preserved covert remembrance of familiar faces. Brain and Cognition, 2, 257-284.

D'Erme P, De Bonis C and Gainotti G (1987) Influenza dell'emiinattenzione e dell'emianopsia sui compiti di bisezione di linee nei pazienti cerebrolesi. Archivio di Psicologia, Neurologia e Psichiatria, 48, 193-207.

De Haan EHF, Young A and Newcombe F (1987a) Face recognition without awareness. Cognitive Neuropsychology, $\mathbf{4}$, 385-415.

De Haan EHF, Young A and Newcome F (1987b) Faces interfere with name classification in a prosopoagnosic patient. Cortex, 23, 309-316.

De Haan EHF, Bauer RM and Greve KW (1992) Behavioural and physiological evidence for covert face recognition in a prosopoagnosic patient. Cortex, 28, 77-95.

Farah JF, Monheit MA and Wallace MA (1991) Unconscious perception of "extinguished" visual stimuli: reassessing the evidence. Neuropsychologia, 29, 949-958.

Gainotti G, D'Erme P, Monteleone D and Silveri MC (1986) Mechanisms of unilateral spatial neglect in relation to laterality of cerebral lesions. Brain, 109, 599-612.

Graf P and Schacter DL (1985) Implicit and explicit memory for 
new associations in normal and amnesic subjects. Journal of Experimental Psychology: Learning and Cognition, 11, 501-518.

Hartmann JA, Woltz WA, Roeltgen DP and Loverso FL (1991) Denial of visual perception. Brain and Cognition, 16, 29-40.

Karnath HO (1988) Deficits of attention in acute and recovered visual hemineglect. Neuropsychologia, 26, 27-43.

Karnath HO and Hartje W (1987) Residual information processing in the neglected visual half-field. Journal of Neurology, 234, 180-184.

Marshall JC and Halligan PW (1988) Blindsight and insight in visuo-spatial neglect. Nature, 336, 766-767.

Paillard J, Michel F and Stelmach G (1983) Localization without content. A tactile analogue of "blind sight". Archives of Neurology, 40, 548-551.

Poeppel E, Held R and Frost D (1973) Residual visual function after brain wounds involving the central visual pathways in man. Nature, 243, 295-296.

Tranel D and Damasio AR (1985) Knowledge without awareness: an autonomic index of facial recognition by prosopoagnosics. Science, 228, 1453-1454.

Volpe BT, Ledoux JE and Gazzaniga MS (1979) Information processing of visual stimuli in an 'extinguished' field. Nature, 282, 722-724.

Weiskrantz L (1987) Residual vision in a scotoma. (A follow-up study of 'form' discrimination). Brain, 110, 77-92.

Weiskrantz L, Warrington EK, Sanders MD and Marshall J (1974) Visual capacity in the hemianopic field following a restricted occipital ablation. Brain, 97, 709-728.

(Received 30 June 1993; accepted 29 July 1993) 


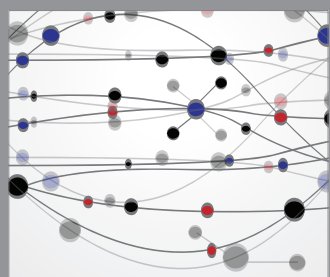

The Scientific World Journal
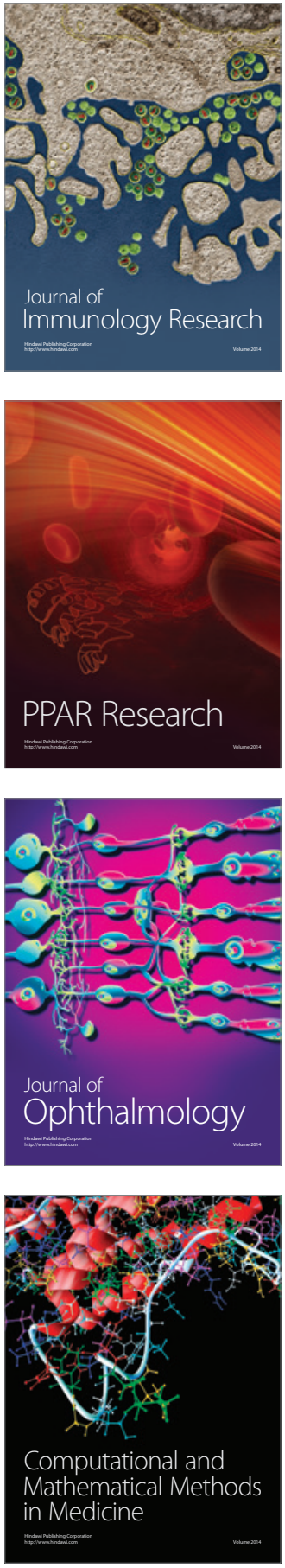

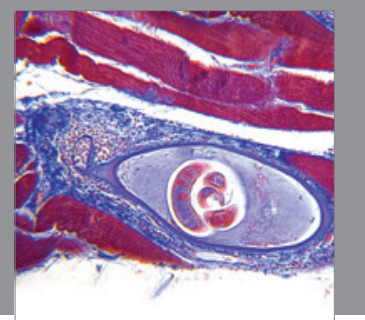

Gastroenterology

Research and Practice
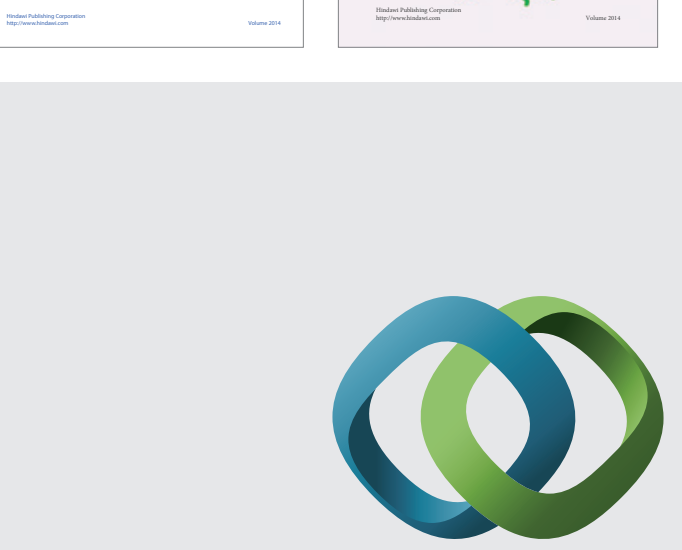

\section{Hindawi}

Submit your manuscripts at

http://www.hindawi.com
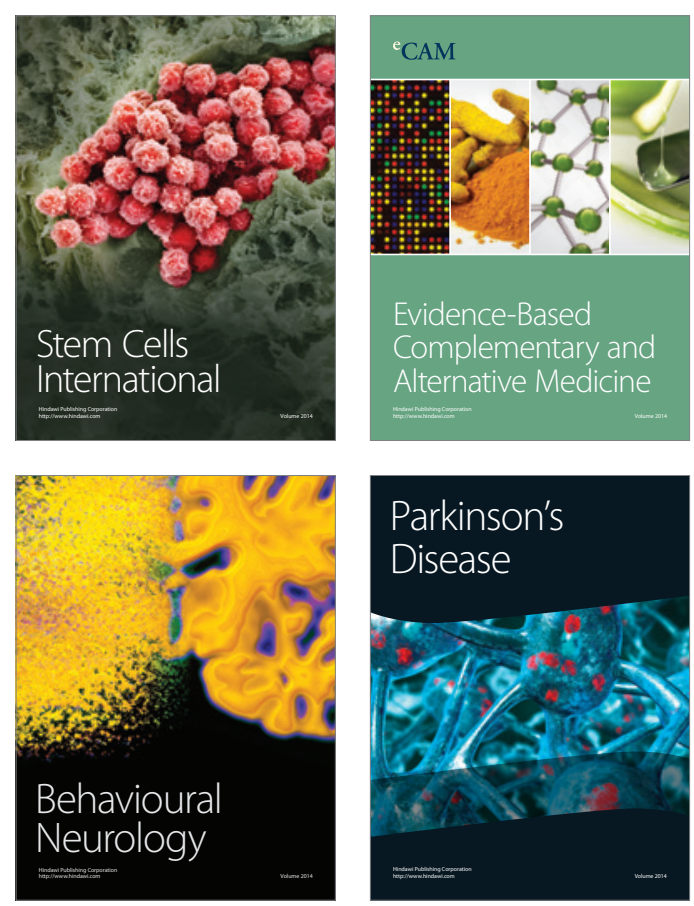

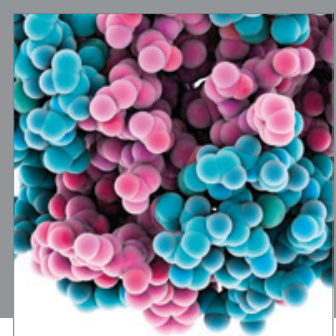

Journal of
Diabetes Research

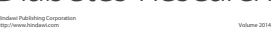

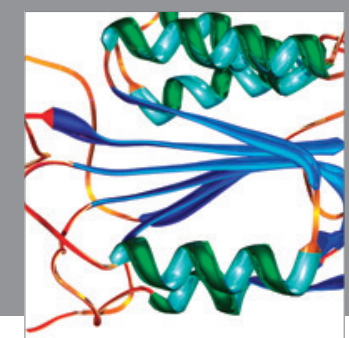

Disease Markers
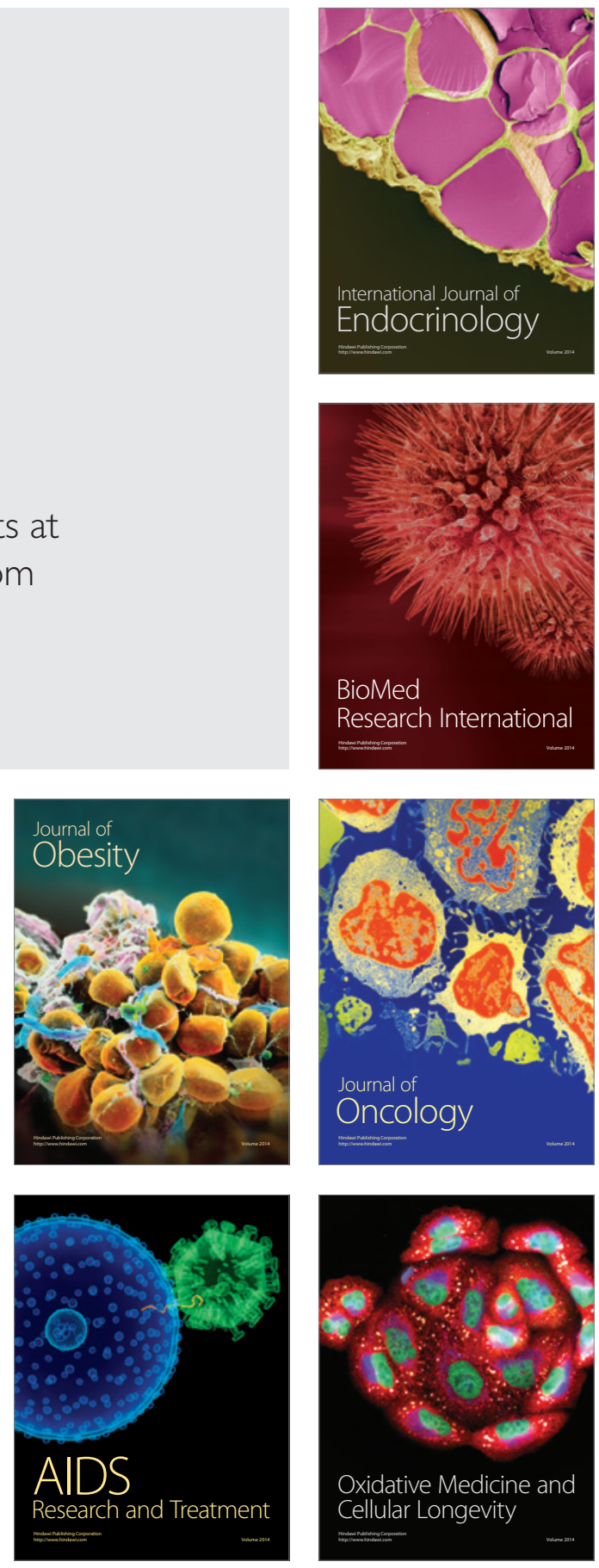